\title{
Probability-based Vendor Selection Model for the Hungarian Automotive Supply Network
}

\author{
Ákos Dömötörfii ${ }^{1 *}$ Zoltán András Nagy², István Árpád Harmati³ \\ ${ }^{1}$ Logistics Society, Veszprém Academic Commission, Hungarian Academy of Sciences, Vár utca 37., H-8200 Veszprém, Hungary \\ 2 Department of Logistics and Forwarding, Audi Hungaria Faculty of Automotive Engineering, Széchenyi István University, \\ Egyetem tér 1., H-9026 Győr, Hungary \\ ${ }^{3}$ Department of Mathematics and Computational Sciences, Faculty of Mechanical Engineering, Informatics and Electrical \\ Engineering, Széchenyi István University, Egyetem tér 1., H-9026 Győr, Hungary \\ * Corresponding author, e-mail: cekaah@freemail.hu
}

Received: 31 January 2021, Accepted: 23 August 2021, Published online: 15 February 2022

\begin{abstract}
The aim of this paper is to investigate the structure of the Hungarian automotive supply network and provide a possible solution that mathematically describes the connections between the interested parties. In the study an approximate model is introduced to determine the links between hubs (car manufacturers), nodes (Tier1 suppliers) and edges, combining probability random graph and scale free network theory. During the simulation some main drivers were applied for selection purposes, such as location, turnover, product profile. As a result of the study a potential tool has been designed to support decision-making.
\end{abstract}

Keywords

automotive, supply network, probability, scale-free networks, random graphs

\section{Introduction}

The automotive supply chain has dramatically changed in the last decades. The industry had to face numerous challenges mainly driven by its complexity and customer diversification, which has led to worldwide supply networks. As part of this globalization Hungary - due to its special geographical and economic situation - plays an important role in the transformation, contributing to investor's growth strategies. However, due to business confidentiality reasons the evolution of these networks is not predictable. To understand the mechanism behind this phenomenon there are certain variables that are part of the network evolution and they have to be considered. Mapping the behavior of these variables probability and network theory implications have been applied in order to define the main characteristics of such a network.

In the research study we examined the Hungarian first level (Tierl) suppliers and the Hungarian car manufacturers (OEMs). The database that was taken into account represents 179 suppliers and 5 car makers (including the upcoming BMW green field plant in Debrecen 2022). For turnover status 2017 data have been considered that is applied at the later stage of the investigation.

\section{Literature}

The globalization implied several studies about automotive industry, however, due to its big size it is impossible to describe the network as a whole. The term network theory is commonly used and is a research topic in many research papers (Péter and Szabó, 2012; 2017), but even a universal definition of automotive supply chain network seems to be difficult.

Supply chain networks are complex systems in their nature. Various authors took the approach to describe the automotive supply network from complexity point of view. Feldhütter et al. (2017) extends the product (manufacturing) complexity to the network, while Nikolopoulou and Ierapetritou (2012) propose a hybrid approach combining mathematical programming and multi-agent based simulation. According to Moyaux et al. (2006) supply chain system can be modeled as a network of agents. Kim and Narasimhan (2019) set up several hypotheses around network evolution driven by strategic alliances between OEMs and vendors. An other study proposed an integrative framework around three central themes: system architecture, system behavior, and system policy control for the network evolution (Bellamy and Basole, 2013). 
Fluctuation of macroeconomics results in change of automobile demand and operation risk. Guo et al. (2016) investigated an optimal channel structure and took uncertain parameters into account to design the supply chain network for the automotive industry. Also in China Wang et al. (2008) investigated the structure of Guangzhou automotive supply chain network based on complex network theory. Their statistical results show that a complex network possessing attributes of small-world and scale-free (Albert et al., 1999), which is one of the key inputs in our study as well.

\section{Theoretical background}

In our concept the supply chain network model of global automotive industry can be described as a combination of random graphs (Erdős and Rényi, 1959) and scale-free networks (Barabási and Albert, 1999).

The degree distribution of a random network follows an approximately normal (Gaussian) distribution, according to which most of the peaks start with a similar amount of edges, and there are no extremely high peaks (degrees). Thus, the random network is similar to a highway network in which the nodes are the cities and the highways connecting them. The power-law distribution of scale-free networks shows that most nodes have only a few connections, which are connected through some stronger hubs that are linked to each other. Visually, this is very similar to air travel, where a large number of small airports are connected through a few large hubs. Some major hubs receive a lot of flights every day. Bigger portion of airports are operating with lower amount of flights and the majority of the airports have less departures. The algorithm can be summarized basically in two rules that are the bases of generating scale-free networks:

1. The number of nodes in the graph is not predetermined but growing.

2. Connections between nodes are not randomly created but preferentially selected.

Applying this to the area of automotive industry, it also has several parallelisms. On the one hand, the large suppliers that are supplying to several car manufacturers, on the other hand in the distribution when the distribution of finished vehicles starts from a car factory in several directions. Scale-free characteristics are also true for them, because not all car manufacturers are served by the same suppliers. It is mainly driven by complexity of the vehicles that is different depending on which car segment they represent, even though the main components of the cars are the same.
The automotive supply chain is not a static object. It is constantly growing with the performance of the world economy and the development of motorization. The scale-freeness therefore lies in the fact that, if a new actor appears in the network, it does not decide where it will be connected randomly, but usually tries to establish a connection with the strongly involved node, that is in this case the car manufacturer. Consequently, one supplier can belong to several Original Equipment Manufacturers (OEM), which leads back to the fundamentals of graph theory. The effectiveness of the network depends on how vulnerable the system as a whole is. Scale-free networks are very robust and difficult to break. The reason for this is that hubs are holding the system so strong that it will work, even if a major hub is falling out.

Mathematically, they are not subject to the theory that previously described how a network is dying (paradigm shift): it has been said that for some time the nodes can be removed, but once a critical value is reached, the network will fall apart.

Scale-free networks do not have critical points. There are many small nodes and only a few big ones. If members fall randomly, the network remains. This also means that hubs can be removed, but the network itself is likely to survive. It is also very likely that the remaining nodes can communicate with each other. In a macroscopic view, the smaller networks within the big network can be self-organized, so each car manufacturer decides for themselves, which vendor they would like to work with. The hubs are present in every network and play a crucial role as they act as linkages between individuals and through them they are linked to each other. Each self-organizing network naturally grows.

\section{Basic model}

As it was demonstrated in the previous chapter, the automotive supply chain network is evolving preferentially, however it still can be modeled as a network where the connectivity is probability based. Erdős and Rényi (1959) described in their study two related variants of the random graph model:

- In the $G(n, M)$ model, a graph is chosen uniformly at random from the collection of all graphs, which have $n$ nodes and $M$ edges.

- In the $G(n, p)$ model, a graph is constructed by connecting nodes randomly. Each edge is included in the graph with probability $p$ independent from every other edge. Equivalently, all graphs with n nodes and $M$ edges have equal probability. 
This theory was taken into consideration as starting parameters to initiate the describing model.

If each supplier is connected to exactly one OEM without any preference, then we actually get a case of the Erdős-Rényi model (Fig. 1, Dömötörfi and Harmati, 2018).

It results in a more complex structure if each supplier can join multiple companies, but the probability of connection is the same (Fig. 2, Dömötörfi and Harmati, 2018).

As a second step we started to iterate the model and influence the selection by the geographical distance between the supplier and the OEM.

We assumed that there is an inverse proportion between the distance and probability of the selection.

$$
P_{s}=1-\frac{s}{700},
$$

where:

$P_{s}$ - probability of connectivity

$s$ - distance of OEM and supplier.

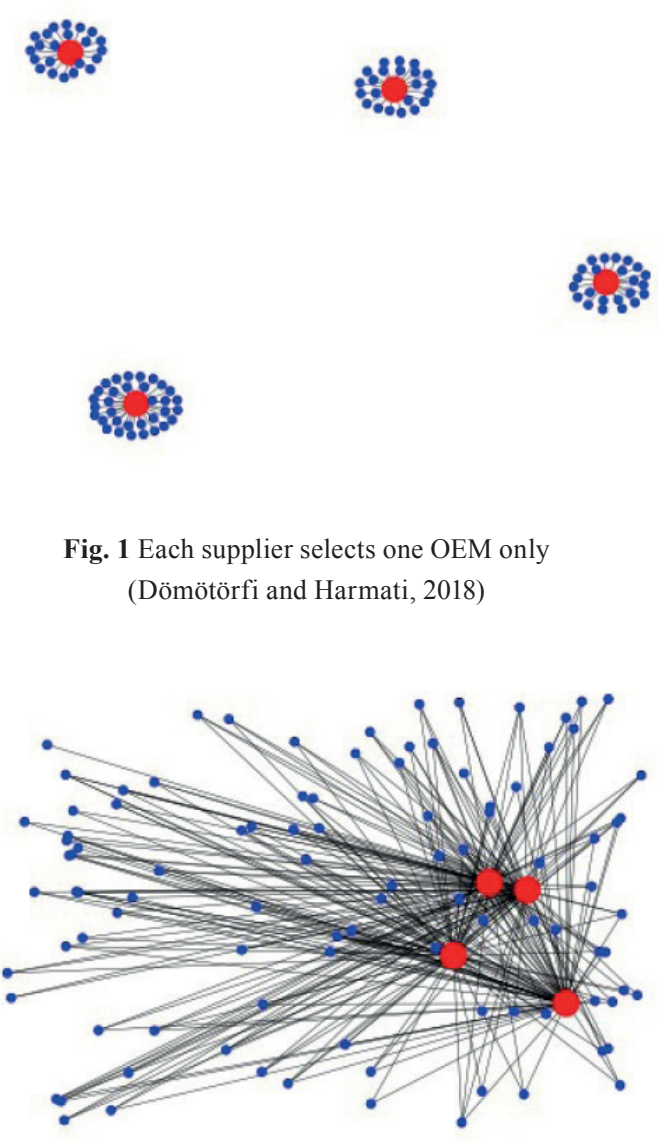

Fig. 2 Connections to various OEMS with same probability (Dömötörfi and Harmati, 2018)
In case of Fig. 3 (a) the model restricts to connect with one OEM only. In option Fig. 3 (b) maximum 2, in option Fig. 3 (c) maximum 3 and in option Fig. 3 (d) there could be maximum 4 suppliers joining to one OEM (Dömötörfi and Harmati, 2018). As none of the scenarios are close to the reality by maximizing the amount of suppliers further variables to be introduced. (Note: the model is not yet considering the $5^{\text {th }}$ Hungarian OEM).

\section{Modeling}

\subsection{Non-linear probability}

The topology presented in the previous chapter focuses on the connectivity model, where the dependence on connection probability is showing linear characteristics. The exact values of these factors are highly influenced by the examined environment, competitors and industry sectors. In this section we will estimate the behavior of these probability parameters and set up a non-linear relation to describe the functionality of the relationship.

In order to determine the probability values, we have chosen functions that have a range of function $(0,1)$ in the definition domain and specify the modeling of the certain factor by non-linear correction.

To describe the distance-dependent probability model of the OEM and supplier connection, it is necessary to have a function that gradually decreases the probability of the connection at the origin $(0 \mathrm{~km})$ while distance is increasing, and after a certain point it shows decreasing trend of the decline. Thus, we could demonstrate the impact of distance in a way, that suppliers in the same region are most likely competing with each other (progressively decreasing phase), while distant suppliers may be competing with each other based on different patterns, where basically the importance of distance is decreasing compared to other factors (degressively decreasing phase). This effect makes the model demonstrable, hence it can be a base for further analysis of not only B2B relationships, but also enables to introduce intra-regional interconnection potentials.

Functions with such properties are also called sigmoid functions (Fig. 4), of which the logistic function has been chosen to define the connection probability (Botzheim and Földesi, 2014). After dividing, stretching, and subtracting the basic function along the horizontal axis with the value taken at 0 , we get the following:

$$
P_{s}=\frac{e^{\frac{-s}{a}}+e^{\frac{-s+i}{a}}}{1+e^{\frac{-s+i}{a}}},
$$




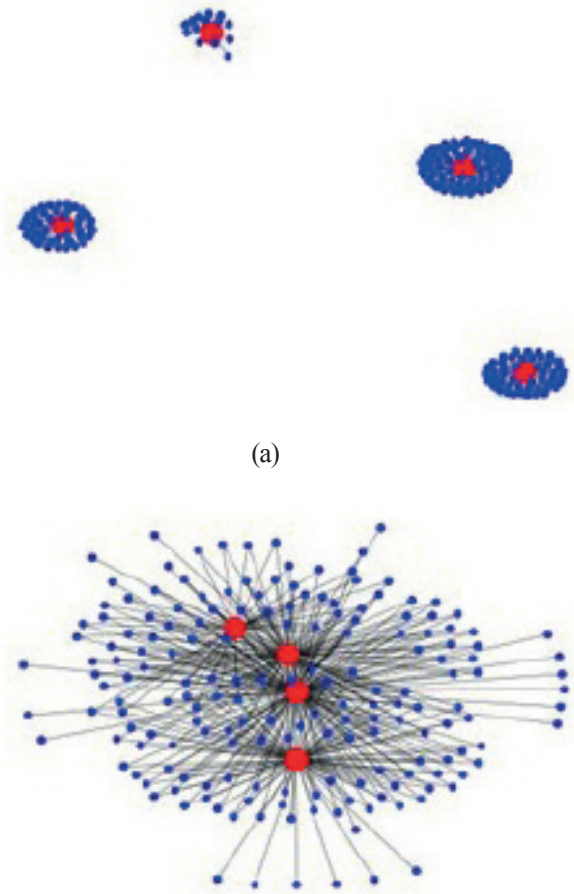

(c)

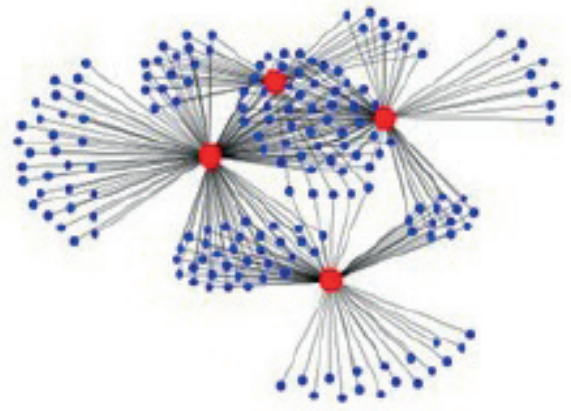

(b)

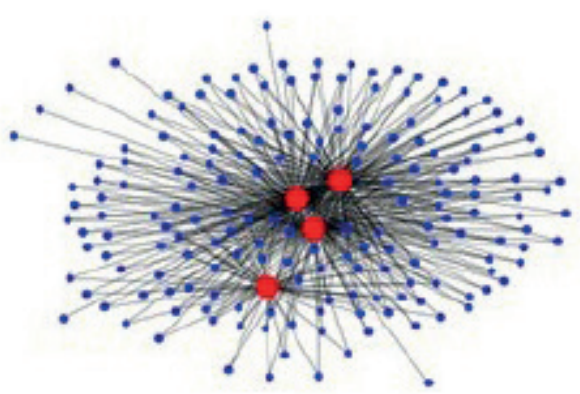

(d)

Fig. 3 Network topology with preferential vendor selection depending on distance and size of the OEM: (a) the model restricts to connect with one OEM only, (b) max. 2, (c) max. 3, (d) max. 4 suppliers joining to one OEM (Dömötörfi and Harmati, 2018)

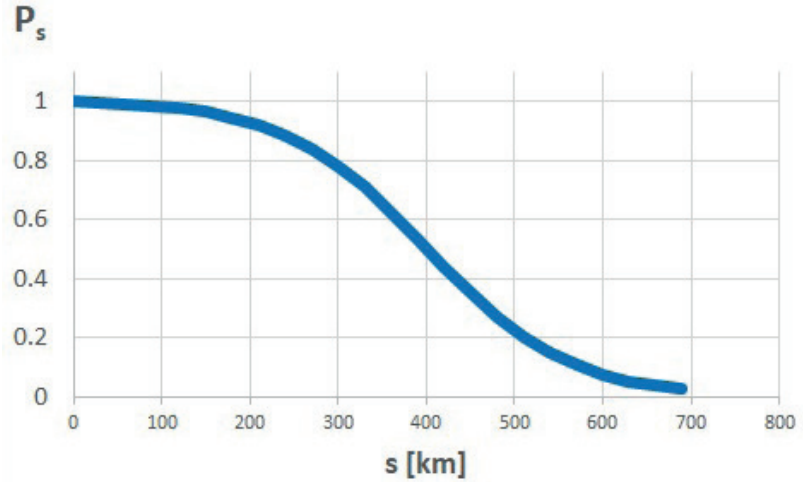

Fig. 4 Sigmoid function describing connection probability based on distance (Own editing)

where:

$P_{s}-$ OEM and supplier distance dependent probability variable

$s$ - distance between OEM and supplier

$i$-inflexion point (horizontal axes offset)

$a$-curve (stretching).

We introduce a second parameter to have an other influencing factor of connectivity probability in the model. This parameter is the size of company which has been dimensioned by the annual turnover of the companies. The linear function is applied to model the OEM size dependent connection probability that is complemented by a correction, which reduces the direct proportion impact of size differences. In order to reduce this effect, we used a logarithmic scale while taking into account the turnover, thus instead of the absolute value of the turnover we examined its natural logarithm.

This correction is applied on OEM and supplier sizes and the following relationship describes the probability variable related to the size of the OEM:

$P_{T 1}=\frac{\ln \left(T_{\mathrm{OEM} 1}\right)}{\ln \left(\sum T_{\mathrm{OEM}}\right)}$,

where:

$P_{T}-$ OEM and vendor size dependent probability variable $T_{\text {OEM1 }}$ - Financial turnover of $\mathrm{OEM}_{1}$.

While selecting the OEM we introduced a criteria analysis (Fig. 5) whether a certain OEM is already occupied by the maximum number of vendors that can be selected or not. While running the algorithm we allowed common suppliers serving different OEMs, furthermore there is a possibility that an already selected vendor is aiming for further relationships.

These probability variables have static values along the given parameters, they retain their values throughout the run of the model, and they remain unchanged even after repeated runs, so they have Markov-properties. 


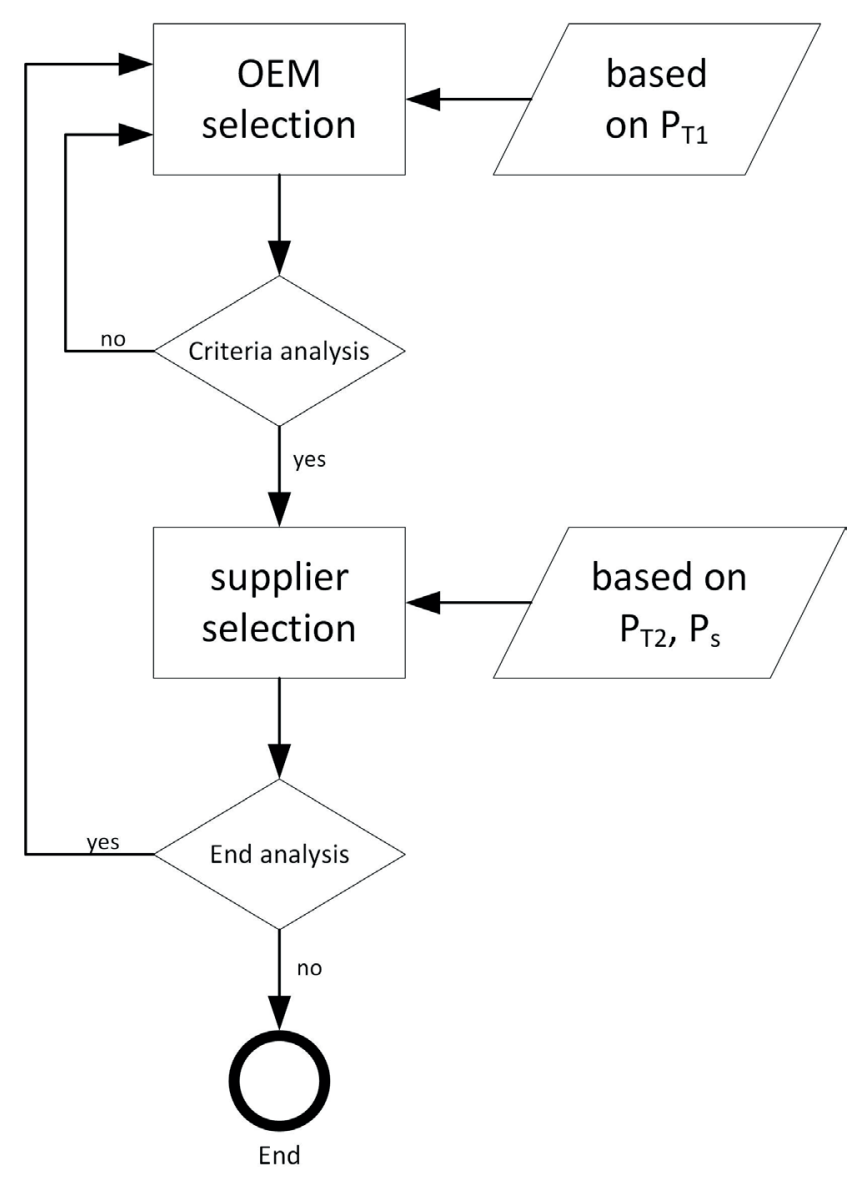

Fig. 5 Flowchart of the basic model (Own editing)

\subsection{Sections}

Restricting vendor selection can be driven not only in terms of quantity, but also in terms of quality. The provision of a certain product/service can only be sourced among those suppliers whose profile is fitting the specific task that must be fulfilled. Therefore, each supplier must carry the attribute that allows to perform the task.

In our model we embedded this function in a way that before the OEM chooses the vendor the related group of products is defined. During the simulation we call the group of products as commodities and we distinguish 14 different categories. This filter allows that the model does not select randomly, but among those suppliers only, who are belonging to the specific commodity. With this scenario we also can set a limit that how many suppliers are allowed to be chosen by a certain OEM. Fig. 6 shows the run of the model changes.

\subsection{Preferential connectivity based on group of companies model}

The elements (nodes and edges) in the connectivity model (Fig. 7) are typically paired with probability variables that have Markov properties and remain unchanged during the

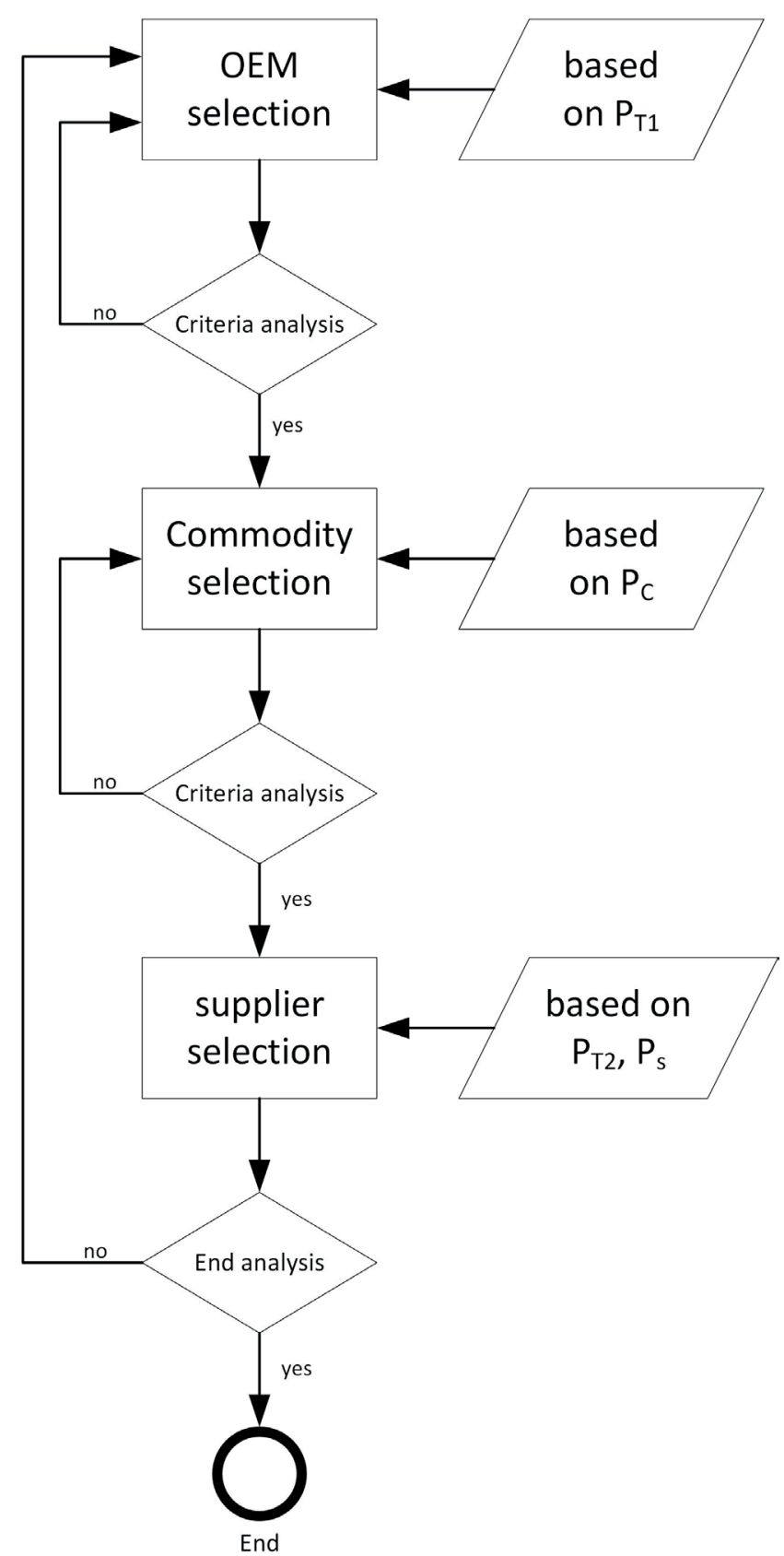

Fig. 6 Flowchart of the commodity restricted model (Own editing)

model run. However, there might be some factors that are carried on during the run and are influencing (directing) the result of the pairing.

In our model (Fig. 8), we present this role through the relationship between OEMs. If there is a good relationship between two OEMs, e.g. sharing of supplier experience, or having joint development programs, or in extreme cases they have the same ownership structure etc., then a supplier's connection to one of the OEMs facilitates joining the other (obviously, this is a runtime boundary and can only be accomplished where multiple OEM relationships with a supplier are allowed). If there is a bad relationship 


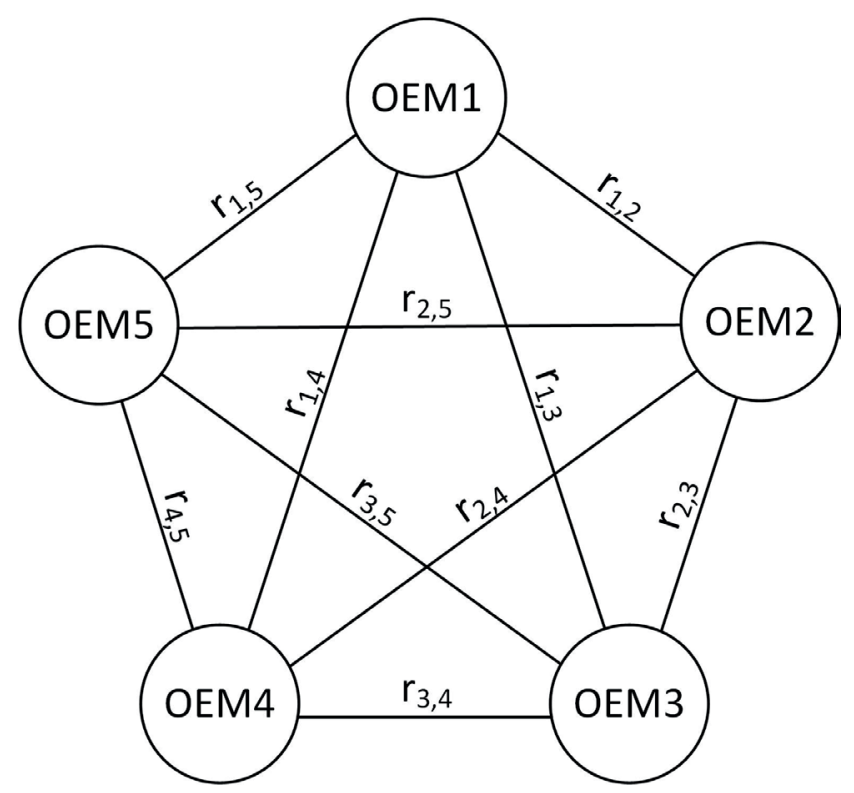

Fig. 7 Graph of OEM s connectivity strength (Own editing)

between the two OEMs, joining one of them reduces the possibility of contacting the other or in extreme cases it is even forbidden (e.g. prohibited contractually) to connect. In Fig. $7 r_{i, j}$ values are showing the quality (strength) of the relationship between the OEMs.

Supply chain is a network of subsystems working together in complex and dynamic environment. To complement the model with this feature, a dynamically changing probability value $\left(P_{k}\right)$ is being implemented, that adjusts the value of the relationship that a particular vendor has already established in the market. With this, the model is losing its Markov property, because past relationships have an impact on the future state.

\section{Conclusions}

The purpose of this article is to model the automotive supply network with random graphs. To build the model, we used the current Hungarian automotive sector as the basis for the model, using data from 5 car manufacturers and 179 suppliers. Non-linear probability functions were applied as factors influencing the car manufacturer-supplier relationships. The primary aspects of the variables affecting the connection preferences were the distance between the actors and their economical size (sales revenue).

The model was further extended by the grouping of suppliers along the same properties and taking into account the principles of sorting these groups together. In this article, this task is performed by assigning suppliers to commodity and then selecting the match.

As a further extension, we considered the features that the participants acquire when running the model, and

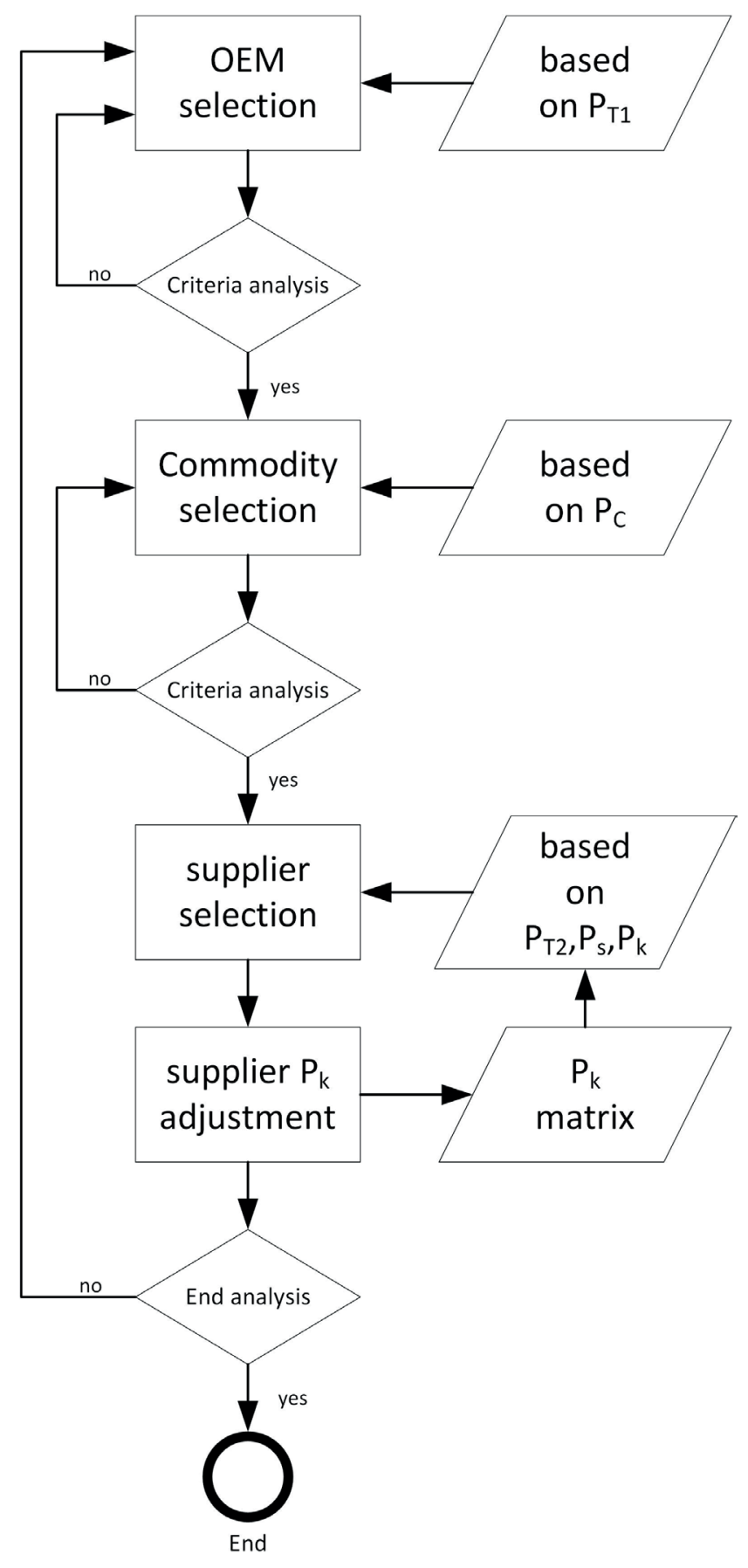

Fig. 8 Modified flowchart considering relationship strengths between OEMS (Own editing)

thus the probability of a possible next selection is changing. In this article, this is represented by the relationship between car manufacturers.

With the model that was developed, we examined to what extent the output of the run changes by the modification of a particular type of connection preference. A further objective was to understand, what impact of a new player can bring and how it would change the results of the initial state. 


\section{References}

Albert, R., Jeong, H., Barabási, A.-L. (1999) "Diameter of the WorldWide Web", Nature, 401(6749), pp. 130-131. https://doi.org/10.1038/43601

Barabási, A.-L., Albert, R. (1999) "Emergence of Scaling in Random Networks", Science, 286(5439), pp. 509-512. https://doi.org/10.1126/science.286.5439.509

Bellamy, M. A., Basole R. C. (2013) "Network analysis of supply chain systems: A systematic review and future research", Systems Engineering, 16(2), pp. 235-249. https://doi.org/10.1002/sys.21238

Botzheim, J., Földesi P. (2014) "Novel calculation of fuzzy exponent in the sigmoid functions for fuzzy neural networks", Neurocomputing, 129, pp. 458-466. https://doi.org/10.1016/j.neucom.2013.09.013

Dömötörfi, Á., Harmati, I. (2018) "Autóipari ellátási láncokon végbemenő kapcsolódások matematikai vizsgálata" (Mathematical analysis of node connections in automotive supply chains), In: XII. Innováció és Fenntartható Felszíni Közlekedés (XII. IFFK 2018), Budapest, Hungary, pp. 389-393. [pdf] Available at: https://mmaws.bme. hu/2018/pages/program/papers/Paper_28_D $\%$ C3\%B6m\%C3\%B 6t\%C3\%B6rfi-Harmati_IFFK_2018.pdf [Accessed: 02 December 2020] (in Hungarian)

Erdős, P., Rényi, A. (1959) "On random graphs I.", Publicationes Mathematicae Debrecen, 6, pp. 290-297.

Feldhütter, V., Steck, C., Hawer, S., ten Hompel, M. (2017) "Impacts of Product-driven Complexity on the Success of Logistics in the Automotive Sector", Procedia CIRP, 62, pp. 129-134. https://doi.org/10.1016/j.procir.2016.06.078

Guo, C., Liu, X., Jin, M., Lv, Z. (2016) "The research on optimization of auto supply chain network robust model under macroeconomic fluctuations", Chaos, Solitons and Fractals, 89, pp. 105-114. https://doi.org/10.1016/j.chaos.2015.10.008
Kim, M. K., Narasimhan, R. (2019) "Designing Supply Networks in Automobile and Electronics Manufacturing Industries: A Multiplex Analysis", Processes, 7(3), Article No.: 176. https://doi.org/10.3390/pr7030176

Moyaux, T., Chaib-draa, B., D'Amours, S. (2006) "Supply Chain Management and Multiagent Systems: An Overview", In: Chaibdraa, B., Müller, J. P. (eds.) Multiagent based Supply Chain Management, Springer, Berlin, Heidelberg, Germany, pp. 1-27. https://doi.org/10.1007/978-3-540-33876-5_1

Nikolopoulou, A., Ierapetritou, M. G. (2012) "Hybrid simulation based optimization approach for supply chain management", Computers \& Chemical Engineering, 47, pp. 183-193. https://doi.org/10.1016/j.compchemeng.2012.06.045

Péter, T., Szabó, K. (2012) "A new network model for the analysis of air traffic networks", Periodica Polytechnica Transportation Engineeering, 40(1), pp. 39-44. https://doi.org/10.3311/pp.tr.2012-1.07

Péter, T., Szabó, K. (2017) "Combined Mathematical Modeling of Different Transport Networks, Considerations and Complex Analysis", Acta Polytechnica Hungarica, 14(2), pp. 7-26. https://doi.org/10.12700/APH.14.2.2017.2.1

Wang, K., Zaofeng, Z., Dongchuan, S. (2008) "Structure Analysis of Supply Chain Networks Based on Complex Network Theory", In: Fourth International Conference on Semantics, Knowledge and Grid, Beijing, China, pp. 493-494. https://doi.org/10.1109/SKG.2008.71 